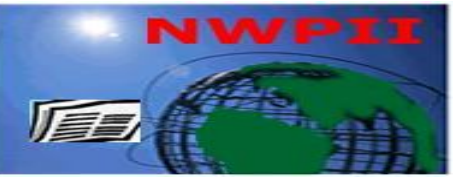

American Journal of Biomedical Sciences

ISSN: 1937-9080

nwpii.com/ajbms

\title{
Inflammatory Response of Lung Derived Cells in Rat Pups Following Intratracheal Surfactant Instillation
}

\author{
Neha Mittal and Sankar Nath Sanyal* \\ Department of Biophysics, Panjab University, Chandigarh-160014, India \\ *Corresponding Author: \\ Dr. S. N. Sanyal \\ Department of Biophysics \\ Panjab University \\ Chandigarh-160014 \\ India \\ Phone: +91-0172-2534122 \\ Email: sanyalpu@gmail.com \\ sanyal@pu.ac.in
}

Received: 10 January 2010; | Revised: 2 April 2010; | Accepted: 12 April 2010

\begin{abstract}
Background: Neonatal respiratory-distress syndrome (nRDS) is a disease that affects the lung functions in premature infants who are born before their surfactant biosynthetic system has matured. Several surfactant-replacement therapies have been developed and are efficacious in treating the RDS.

Objective: The study investigates the inflammatory response of the lung derived cells in rat pups with intratracheal instillation of surfactant (SF), isolated from porcine and the synthetic surfactant.

Methods: Rat pups were divided into three groups: Controls were instilled with buffer, similarly P-SF and S-SF group of animals were instilled with porcine and synthetic surfactant, respectively. Bronchoalveolar fluid (BALF) was isolated and the different cytokines and reactive oxygen-nitrogen species (RONS) were measured using quantitative ELISA and fluorescence spectroscopic methods, respectively.

Results: After $24 \mathrm{hrs}$, cytokines secretions were found to be elevated in the BALF with porcine and synthetic surfactant. Further, nitric oxide (NO) and citrulline levels as well as the reactive oxygen species (ROS) generation were also found to be increased with surfactant administration.

Conclusion: In the treatment of respiratory distress syndrome, the anti-inflammatory response of surfactant may thus depend upon the specific preparation of the surfactant and its administration.
\end{abstract}

Keywords: Citrulline; Cytokines; 2,7-dichlorofluorescein diacetate; Nitric oxide; Rat pups; Respiratory distress syndrome; Surfactant. 


\section{INTRODUCTION}

Lung surfactant is a lipoprotein complex in the alveolar lining whose principal function is to stabilize the alveoli during expiration by lowering the surface tension at air/liquid interface [1]. Insufficient or altered production of surfactant has been associated with the disturbance of alveolar gas exchange, as illustrated by the clinical symptoms of neonatal respiratory distress syndrome (RDS). RDS is a disease that affects premature infants who are born before their surfactant biosynthetic system has matured [2]. A deficiency of surfactant results in increased surface tension at the air liquid interface of the lung and collapse of the alveolar gas-exchanging units of the lung. This makes breathing difficult to the extent that respiration is frequently impossible without ventilatory support and consequently develops significant lung dysfunction if not treated with exogenous surfactant shortly after birth [3]. The situation is further compromised by the development of epithelial necrosis in bronchioles and alveoli, delayed resorption of foetal lung liquid and leakage of surfactant inhibitory proteins into the air space [2].

Tracheal instillation of an appropriate dose of surfactant into such immature neonatal lung results in a lowering of the opening pressure, proportional to the decrease in the equilibrium surface tension of the lung liquid, and to improved stability during deflation. These beneficial effects have been demonstrated in pressure volume recordings from preterm new born in experimental animals treated with (a) crude natural surfactant [4], (b) lipid extracts of natural surfactant containing small amounts of the low molecular weight hydrophobic apoprotein [5], and (c) the extracted surfactant lipids enriched with dipalmitoyl phosphatidylcholine (DPPC), tripalmitin and palmitic acid [6]. Recently, some interesting clinical observations and several animal studies involving transgenic and gene knockout models have further demonstrated the essential role of the various surfactant components, specifically the surfactant proteins for normal lung function [7].

Surfactant replacement therapy is thus, being widely used these days in all hospitals throughout the western world $[8,9]$ both as a prophylactic approach in the newborn infants for the prevention of RDS and as a rescue operation for patients with respiratory failure. Treatment of these babies with exogenous surfactant replacement reduces mortality and morbidity due to this disease but, it has been debated that the risk of immunological sensitisation of patients given heterologous surfactant intratracheally is always there. Lately, it has also been reported that there is an increased risk of pulmonary haemorrhage in extremely low birth weight infants following surfactant instillation and this effect may vary for different surfactant preparations or their dosage [10]. However, it has been argued that since these immature newborns have limited capacity to immunological response, there is no allergic complication following surfactant instillation [2]. On the contrary, there are some studies to show the presence of circulating surfactant antisurfactant immune complexes even after 24-48 hrs following surfactant replacement. But, it has been reasoned that this might be a non-specific phenomenon unrelated to replacement therapy [11].

It has been established that exogenous surfactant in addition to its well documented effects on gas exchange and lung mechanics, also affects the lung cellular defense system [12]. Quite a few in vitro studies have documented an interaction between alveolar macrophages and surfactant in the immunological defense during inflammatory processes in the lungs [13]. It is noted that, shortly after birth large quantities of surfactant are released from the type -II epithelial cells in the alveoli. In association with this phenomenon, Zeligs et al, [14] found a high concentration of phospholipids in the alveolar macrophages. It has also been reported that in conditions with excess surfactant production, the alveolar macrophages become stuffed with lipid complexes and may lose their normal capacity to ingest foreign particles and to generate a burst of oxidative metabolism following phagocytosis [15]. This has been suggested to be a probable mechanism for the decreased bactericidal capacity of neonatal macrophages [16]. The nature of the response of these inflammatory cells to exogenous surfactant and the role of the altered number and 
functions of these cells in the balance of inflammatory lung damage and resolution are not well studied and remain to be elucidated. Therefore, the present study is designed to study the immunological response of the lung inflammatory cells from new born rat pups following surfactant instillation.

\section{MATERIALS AND METHODS}

\subsection{Isolation of surfactant}

Surfactant was isolated from porcine lung homogenate by sucrose density gradient centrifugation. All processes were carried out strictly at $4^{0} \mathrm{C}$. The tissue were homogenised in a buffer that contained $50 \mathrm{mM}$ Tris- $\mathrm{HCl}, \mathrm{pH}-7.4$, $150 \mathrm{mM} \mathrm{NaCl}, 1 \mathrm{mM} \mathrm{NaN} 3$ \& $0.2 \mathrm{mM}$ phenyl methyl sulfonyl fluoride (PMSF) and strained through four layers of cheese cloth. Homogenate was initially centrifuged at $1500 \mathrm{x}$ g for $20 \mathrm{~min}$ to remove the intact cells and other debris. Supernatant was then centrifuged at $20,000 \mathrm{x}$ g for $1 \mathrm{hr}$ and the resulting pellet after resuspending in the above mentioned buffer is layered over $0.75 \mathrm{M}$ sucrose and centrifuged at 74,800 $\mathrm{x} g$ for $1 \mathrm{hr}$ in a $6 \mathrm{x} 12 \mathrm{ml} \mathrm{Ti}$ swing out rotor in a Beckman Ultracentrifuge. The surfactant complex at the interface between the sucrose and buffer layer was removed and washed three times with 10 volume of the buffer by repeated centrifugation at 10,000 $\mathrm{x} g$ for $30 \mathrm{~min}$ [17].

\subsection{Preparation of exogenous surfactant}

It is an aqueous solution of protein free synthetic surfactant consisting of lipid component: Dipalmotyl phosphatidylcholine (DPPC $13.9 \mathrm{mg} / \mathrm{ml}$ ), spreading agent for DPPC: Cetyl alcohol (hexadeconol $1.5 \mathrm{mg} / \mathrm{ml}$ ), and Tyloxapol $(1.0 \mathrm{mg} / \mathrm{ml})$, a non-ionic surfactant which acts to disperse both DPPC and Cetyl alcohol are added. The lypholizate of the surfactant was resuspended in the above mentioned buffer [18].

\subsection{Experimental groups \& instillation of surfactant in rat pups by surgical intervention}

Rat pups of Sprague-Dawley strain, weighing 25-40g were taken from the Central Animal House of Panjab University for all the studies as described here. All the animals were kept in polypropylene cages under hygienic conditions and supplied with pellet diet (Ashirwad Industries, India) and drinking water ad libitum. Control group of animals were administered intratracheally with $50 \mu \mathrm{l}$ of the buffer $(50 \mathrm{mM}$ Tris-HCl, pH-7.4, 150mM NaCl, $1 \mathrm{mM} \mathrm{NaN}$ \& $0.2 \mathrm{mM}$ PMSF). Similarly, animals were given $50 \mu \mathrm{l}$ of porcine SF (P-SF group, $5 \mathrm{mg} / \mathrm{ml}$ ), and synthetic-SF (S-SF group, $5 \mathrm{mg} / \mathrm{ml}$ ). All rat pups were anesthetized with ketamine $(130 \mathrm{mg} / \mathrm{kg}$. i.p.), such that they remained unconscious throughout the entire instillation procedure and had no cough reflex upon intubation. A small incision was made on the ventral region of the neck and the trachea was carefully exposed. Animals were then placed on a slight incline, and a 26-gauge needle was used to instill surfactant into the trachea followed by 2-3 boluses of $1 \mathrm{ml}$ air to facilitate the distribution of the instilled fluid and shortly thereafter, when normal spontaneous breathing was apparent, the neck incision was closed with silk sutures. To avoid any infection the betadine and neosporin powder were applied to the wound area. The animals were sacrificed at 24 hours after buffer or surfactant instillation. All of the animal procedures as reported here followed the guidelines approved by the Panjab University Ethical Committee on the use of the experimental animals for biomedical research.

\subsection{Isolation of BALF}

At the end of each experiment, a bronchoalveolar lavage was performed using $5 \mathrm{ml}$ phosphate buffered saline (PBS, pH-7.4). The average fluid recovery was greater than $90 \%$. The recovered volume was centrifuged at $1000 \mathrm{x} \mathrm{g}$ for $10 \mathrm{~min}$ at $4^{0} \mathrm{C}$ and the supernatants were stored at $20^{\circ} \mathrm{C}$ until analysis. Furthermore, the cell pellet was resuspended in PBS and subsequently the cell number was counted using a Neubayer's hemocytometer. Differential counts were performed on 200 cells stained with Wright Giemsa [19].

\subsection{Cytokines measurement in BAL fluid}

The concentration of IL- $1 \beta$, TNF- $\alpha$, IFN- $\gamma$, IL-2 and IL-4 in pups BAL fluid were measured by using a commercially available ELISA kit 
(Bender Med Systems, CA, USA). Optical density was read at $450 \mathrm{~nm}$ using a microplate reader (MIOS mini, Merck, USA). Standard curve was generated for each individual cytokine (IL-1 $\beta$ $31 \mathrm{pg} / \mathrm{ml}-2000 \mathrm{pg} / \mathrm{ml}$; IL-2 - 63pg/ml-2000pg/ml; IL-4 - $1.56 \mathrm{pg} / \mathrm{ml}-100 \mathrm{pg} / \mathrm{ml}$; TNF- $\alpha-2500 \mathrm{pg} / \mathrm{ml}-$ $39 \mathrm{pg} / \mathrm{ml}$; IFN- $\gamma-2000 \mathrm{pg} / \mathrm{ml}-31.3 \mathrm{pg} / \mathrm{ml}$ ).

\subsection{Determination of nitrate/nitrite by Griess reaction}

NO formation was spectrophotometrically determined measuring nitrite as a stable product with the Griess reaction by a microplate assay method. 100ul of BALF sample was incubated with $100 \mu \mathrm{l}$ of Griess reagent containing $1 \%$ sulfanilamide, $\quad 0.1 \% \quad \mathrm{~N}$-1-naphthylethylene diamine dihydrochloride and $2.5 \%$ orthophosphoric acid for $10 \mathrm{~min}$ at room temperature. Absorbance was measured at $550 \mathrm{~nm}$ using a microplate reader. Sodium nitrite standard curve (1.25nmole-10nmole) was generated to calculate the BALF nitrite concentrations [20].

\subsection{Citrulline assay}

Citrulline level was measured by its reaction with diacetylmonoxime and thiosemicarbazide (chromogenic solution) and absorbance was measured at 530nm. 40 $\mu 1$ of BALF was mixed with zinc sulphate and centrifuged. The $20 \mu \mathrm{l}$ of the supernatant was mixed with $0.1 \mathrm{~N} \mathrm{HCl}$ and with $1.5 \mathrm{ml}$ chromogenic solution, and incubated for $30 \mathrm{~min}$ in a water bath at $100^{\circ} \mathrm{C}$. Citrulline standard curve (5nmole-40nmole) was generated simultaneously [21].

\subsection{Intracellular reactive oxygen species (ROS) generation}

Intracellular ROS was estimated using a fluorescent probe, 2, 7-dichlorofluorescein diacetate (DCFH-DA). DCFH-DA diffuses through the cell membrane readily and enzymatically hydrolysed by intracellular esterases to non-fluorescent dichlorofluorescin (DCFH), which is then rapidly oxidized to a highly fluorescent DCF in the presence of ROS. The cells in the conc. of $2 \times 10^{4} / \mathrm{ml}$ were loaded with DCFH-DA (final concentration $2.5 \mu \mathrm{M}$ ) and incubated at $37{ }^{0} \mathrm{C}$ for $1 \mathrm{~h}$. DCF fluorescence intensity was detected at an excitation wavelength of $485 \mathrm{~nm}$ and emission wavelength of $530 \mathrm{~nm}$ which was found to be proportional to the amount of ROS formed intra-cellularly [22]. The fluorescence intensity was measured in a Perkin Elmer LS55 fluorescence spectrometer.

\subsection{Histopathological observations}

Light microscopic studies were performed in the lung paraffin sections. Lungs were fixed in $10 \%$ formalin for $48 \mathrm{hrs}$, dehydrated in ethanol, cleared in xylene and embedded in paraffin. The tissues were sectioned and prepared for histological analysis, mounted onto a microscopic slide and stained with Hematoxylin and Eosin [23].

\subsection{Statistical analysis}

Statistical analysis was performed using SPSS version 10.0 software (SPSS Inc., Chicago, IL). One way analysis of variance (ANOVA) was done to compare the means between the different treatments using Post-Hoc comparison by Least Significant Difference (LSD) method. A value of $\mathrm{p}<0.05$ was considered significant in the present study. All data were expressed as Mean \pm SD of five animals for each group.

\section{RESULTS}

\subsection{Cytokines level in BALF}

To test whether exogenous surfactant could affect the pulmonary inflammation response, its effects on cytokine levels were determined by ELISA. In control animals, the IL-1 $\beta$ concentration of $433.5 \mathrm{pg} / \mathrm{ml}$ was measured in the respiratory compartment. Upon surfactant instillation, it increased to $631.6 \mathrm{pg} / \mathrm{ml}(\mathrm{p}<0.001)$ with P-SF and was further increased to $1075.6 \mathrm{pg} / \mathrm{ml}(\mathrm{p}<0.001)$ by S-SF (Fig. 1A) whereas IL-2 level was found to be unaltered with surfactant administration. TNF- $\alpha$ concentration increased from $366 \mathrm{pg} / \mathrm{ml}$ in control animals to $446 \mathrm{pg} / \mathrm{ml}$ and $462 \mathrm{pg} / \mathrm{ml}$ in P-SF and S-SF instilled animals $(p<0.001)$, respectively. IFN- $\gamma$ level was found to be $279 \mathrm{pg} / \mathrm{ml}$ in control rats. With instillation of surfactant the IFN- $\gamma$ levels were $386.3 \mathrm{pg} / \mathrm{ml}(\mathrm{p}<0.001)$ in P-SF and $455.6 \mathrm{pg} / \mathrm{ml}$ in $\mathrm{S}-\mathrm{SF}$ group $(\mathrm{p}<0.001)$. Similarly, IL-4 levels were observed to be increased with both the surfactant 
administration in comparison to the control group $(5.74 \mathrm{pg} / \mathrm{ml}$ in control rats, $6.4 \mathrm{pg} / \mathrm{ml}$ with P-SF and $7.23 \mathrm{pg} / \mathrm{ml}$ with $\mathrm{S}-\mathrm{SF}, \mathrm{p}<0.001$, fig. 1B).

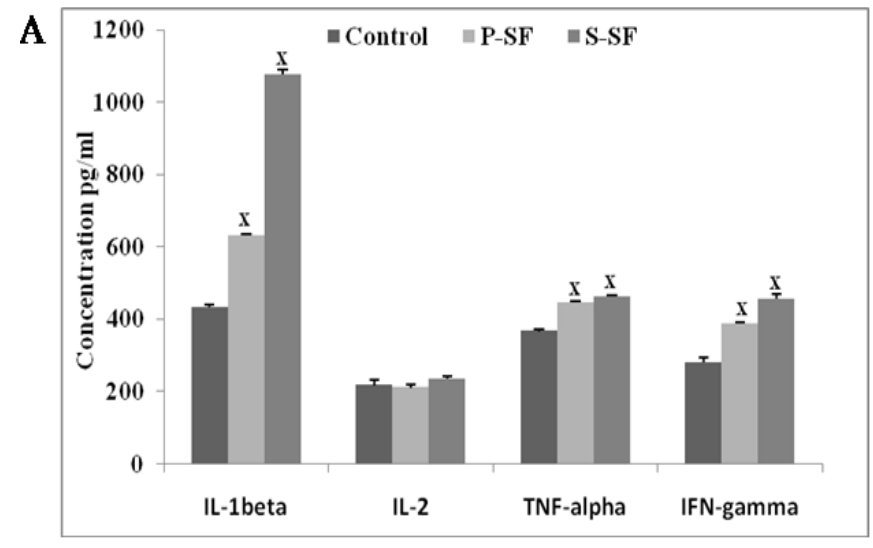

B

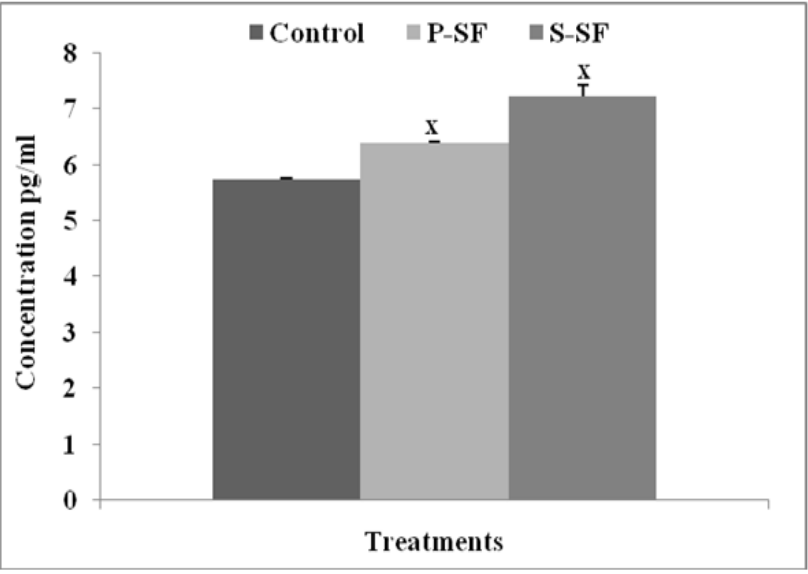

Figure 1. Effect of exogenous surfactant on various cytokines (IL-1 $\beta$, IL-2, TNF- $\alpha$ and IFN- $\gamma$ ) secretion in BALF (A) and on IL-4 level (B) in BALF. Values are mean \pm S.D. of five independent observations $(n=5)$. ${ }^{\mathrm{x}} \mathrm{p}<0.001$ versus control.

\subsection{Effect of surfactants on Nitric oxide (NO) and citrulline production}

NO level was found to be elevated in P-SF and S-SF groups $(0.599 \pm 0.75 \mathrm{nmole} / \mathrm{ml}$ and $0.845 \pm 0.667 \mathrm{nmole} / \mathrm{ml}, \mathrm{p}<0.001$, respectively) in comparison to the control group $(0.456 \pm 0.625$ nmole/ml) whereas no significant change was observed in citrulline levels (Fig. 2).

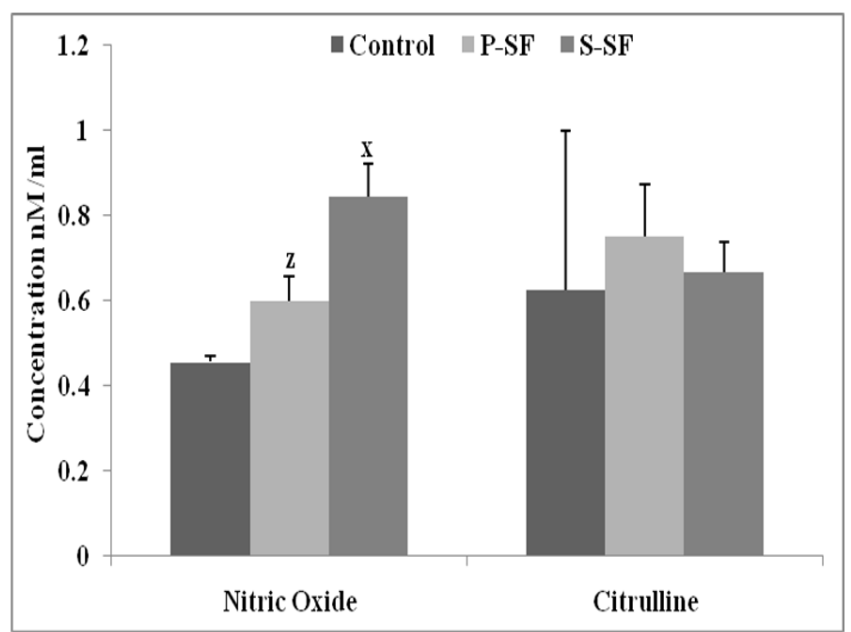

Figure 2. Effect of exogenous surfactants on nitrite and citrulline production. Values are mean \pm S.D. of five independent observations $(n=4) .{ }^{x} p<0.001$; ${ }^{\mathrm{z}} \mathrm{p}<0.01$ versus control.

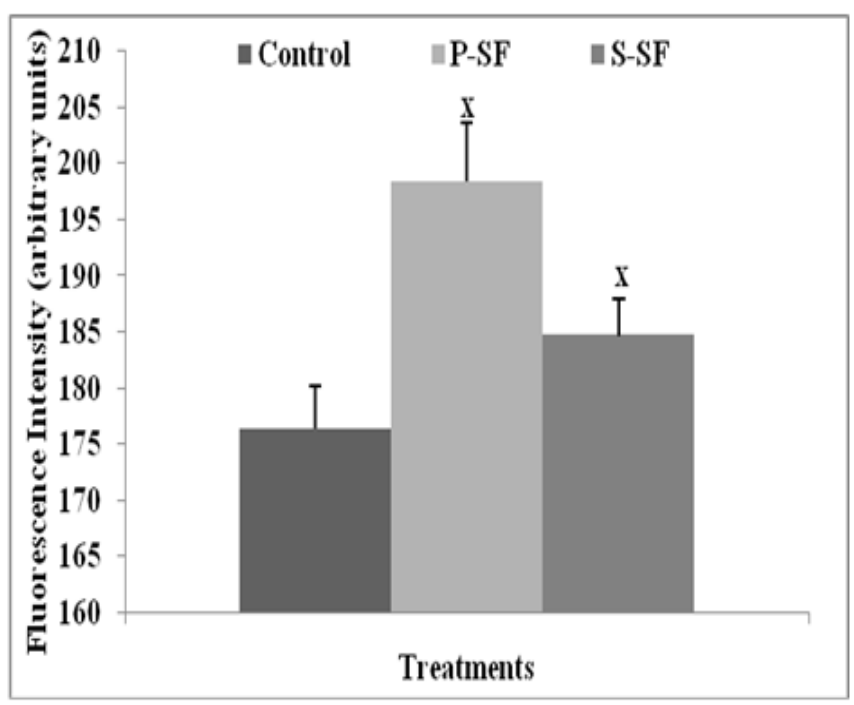

Figure 3. Effect of exogenous surfactants on reactive oxygen species (ROS) generated oxidative burst. Values are mean \pm S.D. of five independent observations $(n=5) .{ }^{\mathrm{x}} \mathrm{p}<0.001$ versus control.

\subsection{Surfactant stimulated oxidative burst}

To assess the effects of surfactant treatment on oxidative burst, AMs were loaded with the fluorescent probe 2'-7'-dichlorofluorescein acetate (DCFH-DA, $2.5 \mu \mathrm{M}$ ). Esterase cleaves the acetate groups of DCFH-DA, thus the trapped DCFH is converted to the highly fluorescent 2'7'dichlorofluorescein (DCF) in the presence of the 
reactive oxygen intermediates. 60 minutes later the fluorescence intensity of the cells was recorded under $485 \mathrm{~nm}$ excitation and green fluorescence from DCF was measured under 530nm emission as shown in Fig. 3. Following surfactant instillations the fluorescent intensity was increased significantly in comparison to the control $(176.37 \pm 3.8)$ indicating that SF treatment significantly impaired the oxidative burst (198.39 \pm 5.2 in P-SF and $184.7 \pm 3.3$ in S-SF, $\mathrm{p}<0.001$ ).

\subsection{Histological examination of lungs}

Massive infiltration of inflammatory cells with neutrophils in the interstitium and alveoli of the lungs with thickening of the alveolar septum were observed in the lungs of both the experimental groups in contrast to the buffer treated controls as seen in Fig. 4. These effects appear to be the most severe in the S-SF group and relatively less in the P-SF group. The reduction in alveolar space (shown by arrows) and vascular congestion were also observed in the treated groups as compared to the control.

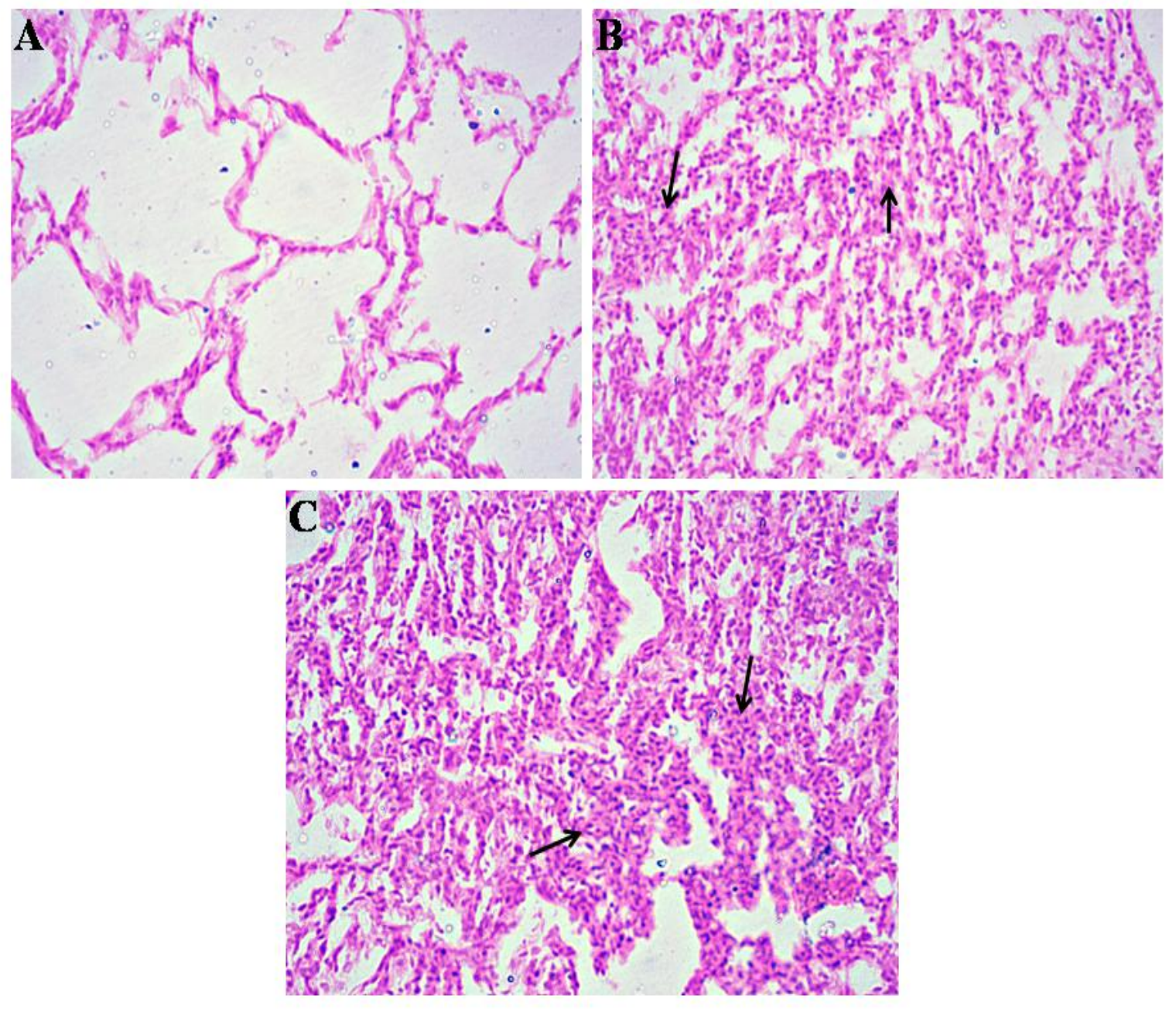

Figure 4. Photomicrographs of histological cross sections of lungs from the different treatment groups after staining with Haematoxylin and Eosin. Control (A), P-SF (B), and S-SF (C).

\section{DISCUSSION}

Am. J. Biomed. Sci. 2010, 2(3), 239-247; doi: 10.5099/aj100300239
In addition to the effects of pulmonary surfactant on alveolar surface tension and lung compliance, it also has immunomodulatory (c) 2010 by NWPII. All rights reserved. 
properties [24]. It is now well established that surfactant therapy is helpful for premature infants with RDS and may be useful in other forms of lung diseases or injury [25]. Therefore, there is much interest in determining whether exogenous surfactant preparations can demonstrate similar anti-inflammatory properties as seen in the native surfactant. The commercially available surfactants for treatment of the newborn with respiratory distress syndrome contain SP-B and SP-C, but do not contain SP-A or SP-D. Increased inflammatory responses seen in the premature new born lung may result from deficiency in host defenses, including low levels of SP-A and SP-D and a relatively low number of macrophages [26]. The present study revealed the effects of a natural surfactant from animal source (porcine) and artificial surfactant (DPPC, cetyl alcohol and tyloxapol) on cytokine secretion, as well as NO production, and oxidative burst with histological examination of the lung tissue.

Our results demonstrate that surfactant instillations increased secretion of the cytokines from the AM, while they elevate the NO production as well. Surfactants also elevated the oxidative burst as observed by the increased ROS generation. The mechanisms by which exogenous surfactants or phospholipids modulate the inflammatory cascade in AMs are unclear [22], possibly the cytokines may play a central role in immune response and pathogenesis [27]. The cytokines levels were found to be elevated in the present study in the BALF of both the treatment groups. IL- $1 \beta$ and IFN- $\gamma$ are early proinflammatory cytokines released by the activated macrophages [28]. Excess release of mediators namely tumor necrosis factor (TNF- $\alpha$ ), IL-1 and $\mathrm{NO}$ are believed to be correlated with the pathogenesis of severe bacterial infection [29]. As expected, rats exposed to the surfactant exhibited a massive recruitment of inflammatory cells in the airways. This cell infiltration was associated with an increase in the levels of cytokines [30].

The induction of NO synthesis during infection is thought to be mediated by the pathogens themselves or pathogen secreted products in synergy with cytokine [31] while AMs represent a major source of $\mathrm{NO}$ production. Also, in vivo studies have shown that TNF- $\alpha$ and IFN- $\gamma$ have a major role in the upregulation of $\mathrm{NO}$ production during infection [32]. Because of its locale within the airspace, the presence of unsaturrated phospholipids and associated proteins, pulmonary surfactant has been identified as a potential target of ROS [33] which is also consistent with our results. It was suggested that in various pathological conditions, a quantitative or even qualitative change of the surfactant phospholipids could lead to an increased accumulation of macrophages in the alveolar space. Surfactant thus has been shown to affect the various functions of alveolar macrophages, monocytes and lymphocytes. These include intracellular killings of microorganisms, production of reactive oxygen intermediates (ROI) [34], and production and release of cytokines [35]. Geertsma et al, [36] have reported that surfactant is involved in the protection of the alveolar epithelium against injury caused by ROI and TNF$\alpha$ and in the down regulation of the production of inflammatory mediators.

These results suggested an attribution of a lipid component to the regulatory mechanisms for immune cells. Immunomodulatory effects of surfactant and its components have been reported and some of them are contradictory, to which our present study supported the regulatory modulations of surfactant on alveolar macrophage functions. In conclusion, this study suggests that instillation of exogenous surfactant may result in a substantial inflammatory and immunological response, in particular, in the AMs which may lead to the modifications in the current protocol of surfactant replacement therapy as followed in various lung injury treatments.

\section{Acknowledgement}

This work is supported by grants from Indian Council of Medical Research (ICMR), New Delhi (Ref. No. 61/5/2005-BMS).

Declaration of interest: The authors report no financial conflicts of interest. The authors alone are responsible for the content and writing of this paper.

\section{References}

(C) 2010 by NWPII. All rights reserved. 
1. Farrell, P.M.; Zachmann, R.D. Enhancememt of lecithin synthesis and PC glyceride transferase activity in the fetal rabbit lung after corticosteriod administration, Pediat Res, 1972, 6, 337.

2. Van Golde, L.M.C.; Batenburg, J.J.; Robertson, B. The pulmonary surfactant system: Biochemical aspects and functional significance, Physiol Rev, 1988, 68, 374-438.

3. Avery, M.E.; Mead, J. Surface properties in relation to atelectasis and hyaline membrane disease. Am J Dis Child, 1959, 97, 517-523.

4. Ikegami, M.; Adams, F.H.; Towers, B.; Osher, A.B. The quantity of natural surfactant necessary to prevent the respiratory distress syndrome in premature lambs. Pediatr Res, 1980, 14, 1082-1085.

5. Metcalf, I.L.; Potoschnik, R.; Burgonyne, R.; Enhorning, G. Lung expansion and survival in rabbit neonates treated with surfactant extract. J Appl Physiol, 1982, 35, 838-843.

6. Jobe, A.; Ikegami, M.; Glatz, T.; Yoshide, Y.; Diakomanolis, E.; Padbury, J. Duration and characteristics of treatment of premature lambs with natural surfactant. J Clin Invest, 1985, 67, 370-375.

7. Glasser, S.W.; Korfhagen, T.R.; Wert, S.E.; Whitsett, J.A. Transgenic models for study of pulmonary development and disease. Am J Physiol Lung Cell Mol Physiol, 1994, 267, L489-L497.

8. Gnanaratnem, J.; Finer, N.N. Neonatal acute respiratory failure. Curr Opin Pediatr, 2000, 12, 227-232.

9. Rodriguez, R.J.; Martin, R.J. Exogenous surfactant therapy in newborns. Respir Care Clin N Am, 1999, 5, 595-616.

10. Strayer, D.S.; Merritt, T.A.; Mukasa, I.; Hallman, M. Surfactant-antisurfactant immune complexes in infants with RDS. Am J Pathol, 1986, 122, 353-362.

11. Wintergerst, E.; Manz-Kainke, H.; Plattner, H.; SchlepperSchafer, J. The interaction of a lung surfactant protein (SP-A) with macrophages is mannose dependent. Eur $J$ Cell Biol, 1989, 50, 291-298.

12. Bellanti, J.A.; Nerurkar, I.S.; Zeligs B.J. Host defenses in the fetus and neonate: Studies of the alveolar macrophage during maturation.
Pediatrics, 1979, 64, 726-739.

13. LaForce, F.M. Effect of alveolar lining material on phagocytic and bactericidal activity of lung macrophages against Staphylococcus aureus. J Lab Clin Med, 1976, 88, 691-699.

14. Zeligs, B.J.; Nerurkar, L.S.; Bellanti, J.A.; Zeligs, J.D. Maturation of rabbit alveolar macrophage during animal development. I. Perinatal influx into alveoli and ultrastructural differentiation. Pediatr Res, 1977, 11, 197208.

15. Haris, J.O. Pulmonary alveolar proteinosis. Abnormal in vivo function of alveolar macrophages. Chest, 1979, 76, 156-159.

16. Golde, D. Alveolar proteinosis and the overfed macrophages. Chest, 1979, 76, 119-120.

17. Suzuki, Y.; Nakai, E-ichi.; Ohkawa, K-ichi. Experimental studies on the pulmonary surfactant. Reconstitution of surface active material. J Lipid Res, 1982, 23, 53-61.

18. Raczka, E.; Kukowska-Latallo, J.F.; Rymaszewski, M.; Chen, C.; Baker, J.R. Jr. The effect of synthetic surfactant exosurf on gene transfer in mouse lung in vivo. Gene Ther, 1998, 5, 1333-1339.

19. Mittal, N.; Sanyal, S. N.; Intratracheal Instillation of Surfactant Inhibits Lipopolysaccharide-induced Acute Respiratory Distress Syndrome in Rats. Am J Biomed Sci, 2010, 2, 190 - 201.

20. Green, S.J.; Crawford, R.M.; Hockmeyer, J.T.; Meltzer, M.S.; Naey, C.A. Leishmania major amastigotes initiate the L-arginine dependant killing mechanism in IFN- $\gamma$-stimulated macrophages by induction of tumor necrosis factor-alpha. J Immunol, 1990, 145, 42904297.

21. Kaur, J.; Sanyal, S.N. Oxidative stress and stress-signaling in chemoprevention of early colon cancer by diclofenac, Am J Biomed Sci, 2010, 2(1), 63-78.

22. Kerecman, J.; Mustafa, S. B.; Vasquez, M.M.; Dixon, P.S.; Catro, R. Immunosuppressive properties of surfactant in alveolar macrophage NR8383. Inflamm. Res, 2008, 57, 118-125.

C 2010 by NWPII. All rights reserved. 
23. Pearse, A.G.E. In Histochemistry, theroritical and applied; Chruchill livingstone: London, 1968; $3^{\text {rd }}$ edn, Vol 1, p-660.

24. Wright, J.R. Immunomodulatory functions of surfactant. Physiol Rev, 1997, 77, 931-962.

25. Suresh, G.K.; Soll, R.F. Overview of surfactant replacement trials. J Perinatol, 2005, 25, Suppl 2, S40-S44.

26. Awasthi, S.; Coalson, J.J.; Crouch, E.; Yang, F.; King, R.J. Surfactant proteins A and D in premature baboons with chronic lung injury: evidence for an inhibition of secretion. Am J Respi Crit Care Med, 1999, 160, 942-949.

27. Ahvazi, B.C.; Jacobs, P.; Stevenson, M.M. Role of macrophage-derived nitric oxide in suppression of lymphocyte proliferation during blood-stage malaria. J Leuko Biol, 1995, 58, 23-31.

28. Thomassen, M.J.; Antal, J.M.; Connors, M.J.; Meeker, D.P.; Wiedemann, H.P. Characterization of exosurf (surfactant)mediated suppression of stimulated human alveolar macrophages cytokine responses. $\mathrm{Am}$ J Resp Cell Mol Biol, 1994, 10, 399-404.

29. Sharma, A.; Kabilan, L. Regulation of nitric oxide production by cytokines in human macrophages: possible role in $P$. vivax malaria. Indian. J Biochem Biophys, 2000, 37, 313-317.

30. Gong, Q.; Xu, J.F.; Yin, H.; Liiu, S.F.; Duan, L.H.; Bian, Z.L. Protective effect of antagonist of high mobility group box 1 on lipopolysaccharide induced actue lung injury in mice. Scand. J Immunol, 2009, 69, 29-35.

31. Weid, V.T.; Kopf, M.; Kohler, G.; Langhorne, J. The immune response to Plasmodium chabaudi malaria in interleukin-4-deficient mice. Eur J Immunol, 1994, 24, 2285-2293.

32. Gazzinelli, R.T.; Eltoum, I. Wynu, T.A. Sher, A. Acute cerebral toxoplasmosis is induced by in vivo neutralization of TNF-alpha and correlates with the down-regulated expression of inducible nitric oxide synthase and other markers of macrophage activation. J Immunol, 1993, 151, 3672-3681.

33. Rodriguez-capote, K.; McCormack, F.X.; Possmayer, F. Pulmonary surfactant protein-A (SP-A) restores the surface properties of surfactant after oxidation by a mechanism that requires the Cys6 interchain disulfide bond and the phospholipid binding domain. $J$ Biol Chem, 2003, 278, 20461-20474.

34. Geertsma, M.F.; Broos, H.R.; Van Den Barselaar, M.T.; Nibbering, P.H.; Van Furta, R. Lung surfactant suppresses oxygen dependent bactericidal functions of human blood monocytes by inhibiting the assembnly of the NADPH oxidase. J Immunol, 1993, 150, 2931.

35. Thomessen, M.J.; Meeker, D.P.; Antal, J.M.; Conor, M.J.; Wiedeman, H.P. Synthetic surfactant (Exosurf) inhibits endotoxinstimulated cytokine secretion by human alveolar macrophages. Am J Respir Cell Mol Biol, 1992, 7, 257.

36. Geertsma, M.F.; Teenne, W.L.; Nibbering, P.H.; Van Furta, R. Pulmonary surfactant inhibits activation of human monocytes by recombinant interferon- $\alpha$. Immunology, 1994, $82,450-456$. 